\title{
A HONRA ESCOLAR: MEMÓRIA MATERIAL DA ESCOLA
}

DOI: http://dx.doi.org/10.1590/2236-3459/52709

\author{
Lisley Canola Treis Teixeira \\ Universidade Federal de Santa Catarina (Ufsc), Brasil \\ Luani de Liz Souza \\ Universidade do Estado de Santa Catarina (Udesc), Brasil
}

\section{$\cos 80$}

\section{Resumo}

Este artigo trata do tema da honra e das penas aplicadas aos alunos nas escolas. No caso específico deste texto, buscou-se reconhecer pela materialidade escolar - "Livro de Honra" do Grupo Escolar Lauro Müller de Florianópolis/SC, datado de 1914 a 1972 (também denominado Livro) - a produção do sentido de honra através dos dispositivos históricos e sociais. Realizou-se uma descrição do Livro e uma interpretação do seu conteúdo, cruzando-o com outros materiais tais como jornais, a legislação educacional e documentos escolares da época. O Livro, como dispositivo, funcionava como normatizador das condutas escolares desejadas, ao mesmo tempo em que honrava aqueles cujo status social já lhes conferia "honra".

Palavras-chave: honra, cultura material escolar, punição.

\section{SCHOOL HONOR: MATERIAL MEMORY OF SCHOOL}

\begin{abstract}
This article deals with the issue of honor and penalties applied to students in schools. In the specific case of this text we sought to recognize the school materiality - "Book of Honor" from Lauro Müller School in Florianópolis/SC, dated from 1914 to 1972 (from now on also called Book) - the production of a sense of honor through historical and social devices in this particular school. A description of the book and an interpretation of its contentes have been done crossing it with other materials such as newspapers, educational legislation and school documents of the time. The Book as a device functioned as a normalizer of the desired school behaviors of the pupils, while honoring those whose social status already gave them "honor".

Keywords: honor, material culture in school, punishment.
\end{abstract}

\section{EL HONOR ESCOLAR: MEMORIA MATERIAL DE LA ESCUELA}

\section{Resumen}

En este artículo se aborda el tema de la honra y de las sanciones aplicadas a los estudiantes en las escuelas. En cuanto a este texto, hemos tratado de reconocer la importancia de la materialidad de la escuela - "Libro de Honor" a la Escuela Lauro Müller, en Florianópolis/SC, de fecha 1914-72 (también 
llamado Libro) - la producción del sentido del honor a través de los dispositivos históricos y social. Hubo una descripción del libro y una interpretación de su contenido, cruzándola con otros materiales como periódicos, legislación educativa y documentos de la escuela de ese momento. El libro como dispositivo funcionó como la normalización de los comportamientos escolares deseados, al tiempo que respeta aquellos cuya condición social ya les dio el "honor".

Palabras clave: honor, cultura material de la escuela, castigo.

\section{L'HONNEUR SCOLAIRE: MÉMOIRE MATÉRIELLE DE L'ÉCOLE}

\section{Résumé}

Cet article aborde le thème de l'honneur et les sanctions appliquées aux étudiants dans les écoles. En ce qui concerne ce texte, nous avons cherché à reconnaître par matérialité scolaire - «Livre d'Honneur" a l'École Lauro Müller Florianópolis / SC, daté de 1914 à 1972 (également appelé Livre) - la production du sens de I'honneur à travers les dispositifs historiques et sociaux. Nous avons fait une description du Livre et une interprétation de son contenu, le croisant avec d'autres matériaux tels que des journaux, des lois sur l'éducation et les documents scolaires de l'époque. Le Livre en tant que dispositif a fonctionné en tant normaliser les comportements scolaires souhaités, tout en honorant ceux dont le statut social leur conférait déjà donné "l'honneur."

Mots-clés: honneur, culture matériel scolaires, la répression. 


\section{Introdução}

Não pode ser, mas é.

O número de páginas deste livro é exatamente infinito. Nenhuma é a primeira; nenhuma a última.

(BORGES, 2009, p. 102).

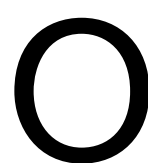

livro de honra na sua materialidade é o dispositivo de análise deste texto. O que se tece neste artigo a partir de um primeiro encontro, de caráter não científico, entre um livro de honra e um casal de amigos que, em épocas diferentes e longínquas, havia deixado seu registro - assinatura, como um dos alunos honrados do Grupo Escolar Lauro Müller da cidade de Florianópolis/SC1.

A reação do casal diante da materialidade escolar foi espantosa, como a de alguém que se depara com uma aparição. O reencontro com a sua caligrafia de infância produziu neles um olhar inusitado. Isto nos remeteu² à expressão aurática de Benjamim (1994) ou mesmo à busca da imagem da mãe no álbum de fotografia que Barthes (1984) se debruça a identificar. Aquela imagem que atrai e fere, pois o que punge o espectador, conforme Barthes (1984), compõe o detalhe.

Os registros escritos no Livro e o Livro deram a impressão de traduzir a imortalidade da sua referência na escola, pois recordaram os amigos da turma através dos seus nomes, o momento da assinatura, os sentidos pertinentes à escola, as relações invisíveis que só os registros não garantem. Ou seja, o Livro, como objeto, e a evidência das assinaturas - traços marcados no passado, suscitaram lembranças diversas.

O casal estava tranquilo ao folhear as páginas do Livro e ao falar sobre o assunto, pois diferente de um livro de penas $^{3}$, que informa os alunos que inflige as regras da instituição, esse produzia uma imagem respeitável e reconhecida no conjunto das práticas escolares na trajetória dos alunos que o assinaram. De acordo com Bourdieu (2004) há um discurso semelhante ${ }^{4}$ sobre a honra e a vergonha, dois tipos de comportamento que

\footnotetext{
${ }^{1}$ Convém situar o período histórico e o universo material da educação que pretendemos apresentar nesse trabalho. O objeto da cultura material escolar baliza-se temporalmente no princípio da criação dos Grupos Escolares em Santa Catarina. O Grupo Escolar Lauro Müller, aqui referido, foi criado em 1912 e a partir de 1914, período que data a criação do Regimento Interno dos Grupos Escolares do Estado de Santa Catarina - Decreto № 795 de 2 de maio de 1914, o art. 197 explicita a forma de mérito para a inscrição dos alunos no Livro de Honra.

${ }^{2}$ Aqui se construiu uma analogia entre imagem e o registro do nome, a assinatura, como obra singular e particular de uma experiência humana vivida. Ainda que não seja uma obra de arte ou uma fotografia. Essa imagem gráfica do próprio nome remete ao sujeito e sua identidade. Produz-se ali o espanto, a emoção no reencontro consigo mesmo. Torna-se objeto do olhar que põe sua identidade e sua presença no tempo e no espaço.

${ }^{3}$ De acordo com o Regimento de 1914, Capítulo VIII, no livro de penas deveria constar os nomes dos alunos que eram encaminhados à diretoria, sendo que só o poderiam fazê-lo se medidas anteriores já tivessem sido tomadas ou caso se tratasse de um fato do qual o diretor deveria ter conhecimento. Alunos com boas notas em comportamento não deveriam ser encaminhados e caso o fossem, devido a algum fato que exigisse ciência do diretor, este aluno precisaria ser acompanhado do seu respectivo professor para que a ocorrência não fosse registrada, sendo o aluno apenas repreendido no gabinete. $\mathrm{O}$ autor, Lucio Vânio Moraes (2008) faz menção a um livro de punições, em uma escola estadual, que entre 1959 e 1972 foi dirigida por religiosas, na qual havia um Livro Negro e outro de Honra. Ali, no caso de três registros no Livro Negro o aluno seria expulso.

4 Bourdieu (2004) ao falar do enraizamento das experiências sociais, de um grupo em particular de seus estudos, esclarece que os indivíduos aderem ou não aos sentidos de honra que se incorporam ao capital simbólico que rege sua instituição ou a sociedade. Todavia, os discursos entre honra e vergonha sempre operam pela categorização do indivíduo como honrado, ao mesmo tempo que aloca outro como não
} 
se entrecruzam na composição dos dispositivos reguladores da honra.

No percurso deste estudo levou-se em consideração a comunicação com alguns egressos, honrados ou não ${ }^{5}$, dessa escola, procurando conhecer os diferentes vestígios sobre as práticas e os sentidos em torno desse Livro.

Algumas pesquisas e publicações, como também documentos oficiais, jornais e fotografias sobre a honra nas escolas do Estado de Santa Catarina e no país, foram perscrutadas para compor as possíveis formas de usos deste dispositivo escolar. Enfim, o que significavam o Livro, seus textos assinaturas e imagens.

\section{As questões da honra}

As proezas e falácias humanas são inventadas em palavras para serem histórias, e uma delas é a honra. Da concepção dual da humanidade livros e homens se inscrevem historicamente nas palavras bem e mal. Códigos e leis instauram-se na trajetória social do homem para conduzi-lo a uma concepção de prudência e êxito específica na experimentação e prática social demarcada pelo corte de classe, étnico, de gênero, religião, época, instituição e nação, como aponta Appiah (2012). Assim, a honra engendrada por certa especificidade, se distingue e/ou assemelha de acordo com as identidades, espaços e tempos. Como Tocqueville (1848) comenta,

O que nossos pais chamavam de arquétipo da honra era, na realidade, apenas uma de suas formas. Davam um nome genérico ao que era somente uma espécie. Portanto, pode-se encontrar honra nos séculos democráticos e nos tempos aristocráticos. Mas não será difícil mostrar que, naqueles, ela apresenta outra face. (TOCQUEVILLE, 1848 apud APPIAH, 2012, p. 179).

Nesse contexto, criam-se códigos múltiplos e multifacetados à honraria que se constitui em um dos dispositivos na sociabilidade, nas experiências e nas práticas, para seguir em direção daquilo que se considera mais aceitável como parte de um tipo de éthos.

As instituições ou as sociedades elaboram constantemente esses padrões, esse conjunto de valores que se espera de uma coletividade. O éthos configura-se na modelação dos capitais sociais, culturais e escolares, no caso da honra fundamenta-se no acumulo do capital simbólico, pois como afirma Bourdieu (2004):

[...] a ideia de lutas pelo reconhecimento são "[sic]" uma dimensão fundamental da vida social e de que nelas está em jogo a acumulação de uma forma particular de capital, a honra no sentido de reputação, de prestígio, havendo, portanto, uma lógica específica da acumulação do capital simbólico, como capital fundado no conhecimento e no reconhecimento. (BOURDIEU, 2004, p. 35-36).

A invenção de um determinado tipo de honra atua na experiência humana porque nela encontram-se os valores enaltecidos, e se constitui em horizontes históricos do caminhar de guerreiros, sábios, sacerdotes e de alguns homens comuns. A honra agrega

honrado. Algo que, no ato da assinatura do Livro de Honra e o próprio sujeito eleito, evidencia a marca também daquele que não alcança a almejada escalada escolar, produzindo entre honra e vergonha, o sentimento da vergonha.

5 Os termos "honrados ou não", aqui se atem aqueles que assinaram o livro de honra e aqueles que não assinaram. 
um conjunto de elementos reconhecidos entre aqueles que comungam um ideal e uma prática social comuns. Nesse sentido, o éthos de cada sociedade e instituição constitui códigos disciplinadores que compõe uma ou outra modalidade de honra. Esses códigos, por sua vez, criam e fazem parte de diferentes dispositivos reguladores do indivíduo e do seu comportamento, nesse caso, para a honra.

Em um sistema social ${ }^{6}$ a honraria opera sobre as ações e nelas destaca as que cabem ao indivíduo no conjunto da sociedade ou no grupo ao qual pertence. Por uma conduta considerada digna e desejada, recebe-se a fama, a posição, o respeito, o prêmio, a homenagem ${ }^{7}$, ou seja, alguma forma de consagração social. Nessa lógica, o indivíduo honrado encontra-se engajado em um sistema e, mais que isto, o fortifica com seus feitos e serve de modelo e idolatria para os demais.

As maneiras como a honra se materializa nas instituições, nos grupos étnicos, religiosos, familiares e no Estado nação, pode se configurar na forma de estátuas, medalhas, eventos e ritos públicos, divulgação do nome e da imagem ${ }^{8}$, quadros, placas e, no caso que abordamos aqui, em um Livro.

Etimologicamente a "Honra se traduz em princípios éticos que leva a uma conduta proba, virtuosa, corajosa, e que lhe permite gozar de bom conceito junto à sociedade." (HOUAISS, 2013). Essa conduta de honra é assimilada nas relações sociais e históricas dos homens e o vestígio disso é também a eminente presença da honraria na escola. Tal honra no universo escolar é trazida à tona, no caso desse estudo, pela materialidade do Livro. Pelos indicativos da legislação e informações de egressos desta escola, os sentidos e práticas em torno do Livro se relacionam a ordenamentos e comportamentos de um fazer educacional.

É possível notar que a glória e a honra estão em destaque na história pela permanência e resistência, seja no formato de livro ou quadro de honra, que resguarda, na memória, os sujeitos que podem gozar do conceito de honrados pelas sociedades e instituições. Porém, trata-se em verdade, de uma seletividade, pois revela as evidências do glorificado, mas oblitera o malogro, os castigos e os infames na História9 ${ }^{9}$.

\section{A honra nas instituições de educação}

$\mathrm{Na}$ cultura material escolar podemos encontrar diversas ${ }^{10}$ referências de

${ }^{6}$ O sistema social de honraria passa sobre o entendimento de que, em um território de temporalidade distinta, almeja-se clivar nas experiências particulares de cada indivíduo um padrão de honra, sendo que um mesmo indivíduo pode ter que operar com práticas distintas de honra. Por exemplo, um aluno opera com a busca da honra escolar e com a honra familiar; um camponês opera com a honra do cultivo da terra e da honra do país, etc.

7 A exemplo, ver livro Memórias de um parlamento - Honrarias concedidas pela Câmara Municipal de Florianópolis (2002), pertencente ao acervo Casa da Memória.

8 Encontramos diversas reportagens sobre a inscrição de nomes em livros de honra de sociedade beneficente onde a contribuição financeira alçava indivíduos à condição de honrados. Em outros casos, os jornais noticiavam até mesmo um livro de honra de inscrições de nomes de escravos que foram libertados. Ver Jornal do Brasil (1911); Jornal O Paiz (1919); do acervo da Hemeroteca Digital da Biblioteca Nacional.

${ }^{9} \mathrm{Na}$ cultura material escolar a permanência e a presença do livro de honra durante longos períodos podem enunciar o desejo pela formatação de um determinado habitus estudantil ou um habitus escolar. A ausência de outros livros, como o de penas, reforça o intuito de apagar da história da escola aqueles que não alçaram êxito na clivagem do habitus escolar.

$10 \mathrm{O}$ mobiliário escolar para a postura e regras nas aulas; a palmatória - castigos; os livros de inspetoria disciplinamento da instituição escolar, estratégias para consolidar um éthos; Prêmios; Quadros e livros de honra - convergem para estruturar um modelo de comportamento, regras de condutas do que é ser aluno. 
estruturação da clivagem de um habitus escolar ${ }^{11}$ almejado pelo sistema educacional. Os dispositivos de emulação disciplinar, como o Livro, transvestem-se de um aparato de reconhecimento e de notoriedade do aluno vinculados diretamente com a disciplinarização. Nas palavras de Foucault (2007) esta "[...] emulação apresenta-se de início sob a forma de um simples reflexo, furtivo, longínquo; percorre em silêncio os espaços do mundo". (FOUCAULT, 2007, p. 28). E assim, nessa situação, o Livro é uma imagem a ser refletida para o espaço escolar, e dispõe-se como um horizonte para a figura do aluno, com todos os sentidos esquadrinhados sobre honra social e escolar.

Nesse sentido, os indicativos legais ${ }^{12}$ e as informações de alunos egressos, apontam que o Livro colaboram na formação do éthos institucional da escola, bem como de um habitus escolar, pois de acordo com Bourdieu (2004):

O habitus, que é o princípio gerador de respostas mais ou menos adaptadas às exigências de um campo, é produto de toda a história individual, bem como, através das experiências formadoras da primeira infância, de toda a história coletiva da família e da classe; em particular, através das experiências em que se exprime o declínio da trajetória de toda uma linhagem e que podem tomar a forma visível e brutal de uma falência ou, ao contrário, manifestar-se apenas como regressões insensíveis. (BOURDIEU, 2004, p. 131).

Não só a honra, como também o uso das punições, são frutos da clivagem de habitus escolar. A maleabilidade e o grau de forças que dão maior ou menor ênfase/peso entre a honra e a punição ficam passíveis de visualização no Regimento Interno dos Grupos Escolares do Estado de Santa Catharina de 1914, através das nuances de como se configuraram algumas das proposições entre honraria e punição, captadas nos seguintes artigos do regimento:

Art. 179. - A disciplina, em todos os assumptos da vida escolar, deverá ser mais preventiva do que repressiva, para o que os professores e os directores explicarão aos alumnos os inconvenientes das suas faltas, de modo a despertar-lhes o sentimento de honra, a ideia do dever, o estímulo e a legítima ambição, antes de usarem dos prêmios e das punições.

Art. 180 - Todavia os alumnos devem saber que serão punidos, quando desobedecerem, e quaes as punições.

Art. 181 - As punições ou penas serão applicadas tendo em vista os preceitos abaixo:

1. que a maneira de serem impostas tem mais importância do que ellas em si mesmo;

2. que sendo impostas sem critério, as melhores tornam-se más;

3. que não devem ser annunciadas com antecedência e nem serem applicadas, enquanto as faltas não estiverem bem provadas;

4. que uma vez prometidas devem ser applicadas.

Art. 182. - O professor deve lembrar que a melhor recompensa, a mais adequada para estimular e nobilitar o alumno, é a de elogiar um trabalho, de modo a convencer ao alumno e aos collegas presentes, de que o elogiado fez

11 Para entender essa construção de um habitus escolar acreditamos ser relevante considerarmos o que Bourdieu (2004) teoriza sobre o habitus em sua produção de cumplicidade com o mundo social, a ideia de um domínio prático das regularidades do mundo. A pretensa de reconhecer no habitus algumas estruturas do mundo social, nesse caso do mundo escolar, que consolida um conjunto de padrões almejados pela sociedade em cada aluno.

12 Artigo 192 do Regimento Interno dos Grupos Escolares do Estado de Santa Catarina, de 1914, explicita as diferenças dos usos do conceito de aluno aplicado, com aproveitamento e comportamento supostamente adequados e as relações de punição e premiação. 
verdadeiramente uma cousa digna de louvor. (REGIMENTO INTERNO DOS GRUPOS ESCOLARES DO ESTADO DE SANTA CATHARINA, 1914)

A honra vinculada a dispositivos escolares, os quais estão relacionados à disciplina na escola, são muito evidentes. Os objetos escolares de práticas disciplinares não estão vinculados diretamente aos modelos disciplinadores que se instalam na escola dita como moderna. Porém, a característica do deslocamento da punição física para uma prática de poder punitivo, estende seus efeitos diretamente na formatação dos alunos que mereçam ser honrados e sobre outros elementos que operam como penas individualizadas. Cabe ressaltar que a suavização punitiva ${ }^{13}$ está tramada sobre novas práticas de poder que se instalam nas instituições escolares, práticas essas que por vezes se apresentam em diferentes formatos, gradações e pesos.

Segundo Gouvêa (2008), tais dispositivos regulam a ação do indivíduo e constroem, no interior das instituições escolares, a individualização de cada aluno por categorizações sociais identificadas em registros escolares. A autora destaca que nas instituições escolares de Minas Gerais entre os séculos XVII e XIX, pode-se reconhecer como as categorias sociais de filiação, idade, moral, de classe, étnica e aparência são registradas e marcadas no percurso escolar do aluno desde os registros de matrícula, de frequências, nas atividades e materiais usados em sala de aula, nas práticas e até no processo de avaliação.

Em São Paulo, em 1894, consta no Regimento Interno que no evento de troca de escola é necessário apresentar informações sobre quão aplicado é o aluno, qual o seu aproveitamento e o porquê da troca de escola. Em Santa Catarina, no Regimento Interno de 1911, cabe ao professor tomar notas diárias do comportamento e aplicação de cada aluno na folha de chamada.

Nos documentos de orientação e ordenamento de instituições escolares pode-se captar alguns aspectos referentes à disciplina e aos mecanismos utilizados para o controle social do indivíduo no âmbito escolar. Os livros de escrituração, apresentados na maior parte dos regimentos escolares que analisamos, operavam como um instrumento político cuidadosamente organizado, e deveriam funcionar como um instrumento de sujeição, sem apelar para o uso da força física. Alguns desses livros são evidências do privilégio e do reconhecimento que emanavam deles, pois trata-se de um conjunto de estratégias manifestadas por uma instituição que reconduz os alunos à posição ou ao padrão que deveriam ser alçados.

Contudo, conforme o contexto, a época e as instituições, os significados e os meios de disciplinamento se modificam, tanto em relação ao peso que dão aos castigos e punições quanto aos prêmios e a honraria. Além disso, o próprio sentido e critérios de punição, prêmio e honraria vão se modificando, sendo que a cultura escolar de cada

\footnotetext{
13 Foucault (2008) menciona, nos estudos dos mecanismos punitivos da justiça criminal, a maneira como uma mudança da aplicação das penas se configura como elemento de outra forma de processos de poder. Segundo o autor "[...] o corpo é investido por relações de poder e de dominação, mas em compensação sua constituição como força de trabalho só é possível se ele está preso num sistema de sujeição (onde a necessidade é também um instrumento político cuidadosamente organizado, calculado e utilizado); o corpo só se torna força útil se é ao mesmo tempo corpo produtivo e corpo submisso". (FOUCAULT, 2008, p. 25-26). Isto é, o que antes era força explicita de submissão, como os castigos corporais, torna-se mais (in) visível ao corpo por ter a suavidade de uma regra condicionante do discurso de ênfase para honra e não como uma ação de violência física.
} 
instituição constitui particularidades que as distinguem, apesar de possuírem uma uniformidade legal.

Essas singularidades, de aplicação e modelação da honra, podem ser notadas nas diferentes instituições que se dedicaram a educação. Encontramos no Ratio Studiorum, código ou método de educação Jesuítica, a constituição de uma glória e uma honra a Deus. Nesse sentido, a honra e a punição são de caráter divino e ambas consagradoras. Com essa perspectiva a disciplina é operada pela divindade.

Já em 1827, no período do Império, na instrução pública, os castigos são praticados no método Lancaster ${ }^{14}$ sob uma sistemática de disciplinamento rígido, de base militar. De outro modo, como parte do processo de disciplina escolar, havia os prêmios. A conhecer também, como parte do método Lancaster, podemos observar na sua legislação o ordenamento dos prêmios do Colégio Pedro Segundo ${ }^{15}$ no Rio de Janeiro, em 1838:

Art. 32 [...] conferirá aos três alumnos mais distinctos de cada anno, por ordem de merecimento, hum $1^{\circ}$, hum $2^{\circ}$, e hum $3^{\circ}$ premio.

O primeiro premio consistirá: em hum livro de encadernação dourada, e em huma coroa entretecida de louro e café.

O segundo premio: em hum livro de igual encadernação.

O terceiro premio: em hum livro de encadernação menos rica.

Neste julgamento a Commissão terá em muito especial consideração as informações do Reitor, do Vice-Reitor, e dos Professores do Collegio, sobre o procedimento, applicação e assiduidade dos alumnos. (Grifo nosso).

Segundo os estudos de Castanha (2009), acerca dos castigos e premiações na escola primária do Século XIX, as práticas punitivas extrapolavam as orientações legais e que este foi um período regido por certa violência. $\mathrm{O}$ autor salientou ainda que para isso prevalecia mais o castigo do que a premiação.

Contudo, na legislação, a partir do período republicano, houve uma significativa redução da aplicação do castigo físico a partir da Reforma de Benjamin Constant em 1890 e a introdução do método intuitivo. Mesmo assim, a honra continua a operar como um dos dispositivos escolares orientados por outras práticas tais como:

Art. 46. Dentre os alumnos do estabelecimento approvados com distincção em todos os exames do anno a congregação escolherá os tres melhores e conferirIhes-ha solemnemente tres premios, com a classificação de $1^{\circ}$, $2^{\circ}$ e $3^{\circ}$. Além disto, em uma sala de honra do externato e outra do internato, denominada Pantheon, serão collocados os retratos dos alumnos, que se houverem tornado credores desta alta e excepcional distincção pelo seu talento, amor ao trabalho, procedimento exemplar e mais virtudes. A congregação será o juiz soberano nesta escolha. (DECRETO № 981, 08 de novembro de 1890). (Grifo nosso).

Dentre os desdobramentos dessa legislação republicana, que reverberam na prática, há a fundamentação de uma hierarquia dos indivíduos na escola. Em uma estrutura como a da escola, o poder-saber é consequencia, não só da própria apropriação do saber, mas de um jogo social sobre a operação com o saber, conforme assinalou

14 Conforme Castanha (2009), esse método foi elaborado pelo inglês Joseph Lancaster no século XIX, quando as elites vinculadas ao Estado necessitavam controlar as classes que se submetiam a elas. Desta forma, no Brasil, o Método Lancaster sintetizava os ideais de unificação durante o império.

15 Manteve-se a grafia conforme exposto na legislação de 1838. 
Foucault (2008):

Temos antes que admitir que o poder produz saber (e não simplesmente favorecendo-o porque o serve ou aplicando-o porque é útil); que poder e saber estão diretamente implicados; que não há relação de poder sem constituição correlata de um campo de saber, nem saber que não suponha e não constitua ao mesmo tempo relações de poder. (FOUCAULT, 2008, p. 27).

As regras e os regimentos escolares assinalam certa hierarquização dos sujeitos, seja pelo saber, seja por outras formas de coadunar os padrões de regras e as intenções desejadas. Classificar os sujeitos do saber vincula-os a um certo poder, nesse caso o do reconhecimento. Esse trabalho de categorização é explicito em todo o mundo social, de forma sistemática, constituindo uma necessidade eminente de publicizar e operar com os efeitos decorrentes da constituição hierárquica que aparecem nos dispositivos disciplinares. Para Bourdieu (2007) essa explicitação

[...] faz-se sem interrupção, a cada momento da existência corrente, a propósito das lutas que opõem os agentes acerca do sentido do mundo social e da sua posição nesse mundo, da sua identidade social, por meio de todas as formas do bem dizer e do mal dizer, da bendição ou da maldição e da maledicência, elogios, congratulações, louvores, cumprimentos ou insultos, censuras, críticas, acusações, calúnias, etc. Não é por acaso que katègorein de que vêm as nossas categorias e os nossos categoremas, significa acusar publicamente. (BOURDIEU, 2007, p.142).

O Livro cheio de presenças marcadas pelos registros das crianças de outrora, que confirmaram sua identidade com a escrita de seus nomes, autoridades que dão o estatuto de autenticidade ao mérito dado, texto com informação legal e uma iconografia, funciona como um estado explicito dos objetivos individuais e coletivos por excelência da escola. Ele constitui, pela categorização hierárquica dos indivíduos, uma forma de perceber esse mundo social da escola, e reforça, detém diretamente um vínculo entre o estado de saber e de poder. Assim, parece ser enunciado nesse objeto/memória escolar - livro de honra, alguns sentidos de identidade, um éthos individual ou coletivo ${ }^{16}$ de honra.

Contudo, o tema da honra nas instituições escolares apresenta matizes próprias, conforme o tipo de instituição, sua época e materialidade. Segundo Appiah (2012) a honra está relacionada com a questão do respeito, de diversos tipos, nem sempre com códigos de base moral. Também a estima, criada por meio da honra, envolve por vezes a eficiência do indivíduo sobre uma atividade ou um reconhecimento. Nesse sentido, para que seja respeitado, faz-se necessário certo comportamento que corresponda às exigências dos pares que participam do mesmo código.

A Reforma Couto Ferraz de 1854, Art. $88 \S 2$, que se refere ao pagamento das taxas, determinava que os alunos pobres que tinham se distinguido por talento, aplicação e moralidade ficassem isentos do pagamento da taxa. Mesmo em relação às punições, a questão do respeito ao outro fica evidente, vejamos: no Art. 72 da mesma legislação, consta que o aluno será expulso, nos casos "incorrigíveis que podem prejudicar os outros, por exemplo, ou influência." A estratégia contida em tal legislação é orientada para que os alunos controlem seus pares. O que está em jogo é o senso de honra de um aluno para

${ }^{16} \mathrm{O}$ conceito de éthos se reporta a Escolano (2012). 
com o outro e para com a instituição. Nesse texto legal fica tácito o jogo de eficiência, produtividade e de reconhecimento que impera sobre a honra escolar.

No Regimento Interno dos Grupos Escolares de 1911 de Santa Catarina, a materialização da honra ocorre através do quadro de honra segundo o Art. 40 - "Serão admitidos os seguintes prêmios, além de outros que melhor pareçam aos diretores: [...] 4은 - a inscripção do nome do alumno em quadro denominado de honra". Desse material, que operava as primeiras formas de honra na escola, não há nenhum vestígio, por hora. Porém, por que o Livro de Honra perdurou por épocas diferentes e por que houve múltiplos sentidos da honra? O que há de memória material da escola quanto a modelação da honra nesse Grupo Escolar?

\section{Objeto memória}

O livro como objeto, parte ou fragmento da memória, representa uma das formas de produção de honra na escola. O Livro de Honra é criado nos Grupos Escolares em Santa Catarina, constituindo-se como um objeto memória ${ }^{17}$ específico, que materializa um sentido educativo vinculado à práticas honradas.

Entretanto, é preciso esclarecer que outras formas compuseram a honra no campo da educação e no meio escolar. Há o quadro de honra e os sistemas de premiações, cujas informações encontradas a respeito datam do final do século XIX no Rio de Janeiro ${ }^{18}$.

Em São Paulo, no jornal O Paiz, de 10 de junho de 1910, ao informar o início da reforma da instrução do estado, a matéria do dia discorre que seria criado um livro de honra destinado aos professores, para se registrar nele quais docentes apresentavam maior distinção no desempenho de seu cargo.

Em Santa Catarina, os estudos de Gladys M. G. Teive (2009) e Vera Lucia Gaspar da Silva (2000) explicitam a existência de um livro de honra para os professores. Conforme texto do jornal O Dia, de três de maio de 1911, em Florianópolis, ao publicar o Regulamento da Instrução Pública com o Decreto n. 585 de 19 de abril de 1911, o Capítulo VI, art. 31 sugere a criação desse livro, estando essa parte do material da Diretoria de Instrução, sob a competência da direção dos grupos escolares.

No livro de honra, seja de professores ou de alunos, residem códigos de valores sociais e morais, que implicam na função do disciplinamento social almejado pela escola, ou seja, há no objeto, segundo Escolano (2012):

[...] trabajo material de creación y de transmisión de saberes genera um cierto ethos indiviadual y colectivo que se comunica en los espacios de sociabilidad que comparten los miembros de los grupos afectados, los usuarios y las

\footnotetext{
17 Objetos-huella conceituado por Escolano (2010) foi aqui traduzido como objetos-memória, pois parece mais adequado ao tecer considerações a respeito da materialidade produtora de um éthos e de um objeto que tende a reverberar uma memória homogênea sobre as experiências distintas acerca da honra.

18 Os dispositivos de honra e/ou premiação estão presentes na maior parte das legislações da educação que compõe o início da República, ou antes, ainda, no que tange o Colégio Pedro Segundo no Rio de Janeiro. Sendo assim, vamos referendar somente algumas legislações que se fizeram evidentes nesse momento de pesquisa. Código de Ensino do Paraná (1917) Art.92 e 93; Código da Instrução Pública de São Paulo (1857) Art. 188 a 199; Decreto № 52 de 1897; Decreto № 38 de nove de maio de 1893 - Rio de Janeiro; Decreto № 3.890 de 1901; Decreto № 11.530 de 1915; Decreto № 1556 de 1855 (Regulamento Colégio Pedro Segundo); Reforma do Ensino Primário de 1883 e outros.
} 
corporaciones, esto es, entre todos los sujetos que cohabitan - o han cohabitado em los lugares que sirven de escenaria a los trabajos ya los ritos que ellos desempeñan y representan. (ESCOLANO, 2012, p. 15).

Essa prática escolar busca imprimir a esse objeto uma identidade de um "sentido da imagem de si, para si e para os outros" (POLLAK, 1992, p. 5). No objeto livro de honra há dois modos distintos de atribuir esse sentido da imagem de identidade, seja a honra como atributo individual, ou honra com relação às solidariedades sociais, conforme os estudos sobre a honra de Pitt-Rivers descritos por Rohden (2006). No caso desse objeto, que agrega um poder narrativo de memória, de uma prática escolar que concatena os sentidos escolares ao disciplinamento social, é possível produzir uma narrativa de glória e de uma escola eficiente.. Conforme o exposto por Pesez (2005):

A cultura material faz parte das infraestruturas, mas não as recobre; ela só se exprime no concreto, nos e pelos objetos (sendo aliás o próprio homem, em seu corpo físico, um objeto material), pois o homem não pode estar ausente quando se trata de cultura. (PESEZ, 2005, p. 242).

Aliás, é dessa forma que a cultura material é produtora de sentidos e a honra é um sentido exposto por essa cultura escolar. Esses sujeitos escolares que experienciam uma relação com essa materialidade, passam a disseminar honra pela materialidade do livro de honra - o sujeito escolar por excelência. Os relatos da professora Abel Beatriz Pereira $^{19}$, sobre a questão da honra em sua infância, mostram como se configura 0 sentido de reconhecimento e excelência diante da classe em torno da honraria:

Tinha um quadro negro - que era como eles chamavam -, um quadro especial. $\mathrm{Na}$ sala de aula tinha dois quadros. Um era para usar esporadicamente, e nele constava a relação dos melhores alunos da classe. Não tinha grandes premiações. Mas eu lembro bem disso, que constavam ali os nomes dos melhores alunos da classe, no bimestre ou no mês. Mas tinha também uma coisa pior do que hoje, a prova. A prova era rigorosa, oral. Além da prova escrita, havia uma oral. Juntava uma bancada, geralmente os diretores do Grupo Escolar presentes. E era assim: o melhor aluno daquele bimestre figurava no quadro de honra. Era uma grande satisfação, um prazer muito grande estar nesse quadro. Era uma honra. Isso gerava até uma certa concorrência entre os alunos, porque cada um se empenhava mais, tinha que estudar para ir para o quadro de honra. (Grifo nosso).

A identidade do aluno precisa se amalgamar com a do coletivo, na qual a honra e os outros dispositivos escolares são os meios para tentar homogeneizar e disciplinar as diferenças (na aprendizagem, no comportamento, no sentimento, na cultura...) diante do coletivo. O que explicita o quanto "a identidade individual projeta-se na identidade de grupo". (SOUZA, 2009, p. 317). Com a escola organizada por séries, em que as crianças estão reunidas em suas classes por grupos etários, por vezes tem-se muito a dizer sobre a honra para os honrados e consagrados e pouco àqueles que não "chegaram ao topo".

O Livro, ao contrário da maior parte dos objetos que compõem a estrutura escolar, que eram (ainda o são) produzidos industrialmente, era elaborado pelo próprio Grupo Escolar Lauro Müller, sendo um artefato da cultura material que não estava diretamente associado à maquinaria industrial, uma vez que era construído estética e

\footnotetext{
${ }^{19}$ Relato extraído de Silva; Shueröff (2010).
} 
estruturalmente na escola a partir de caderno de atas.

Desse modo, de acordo com Frago (1995, apud SOUZA, 2007, p. 165), "o aparecimento, o uso, a transformação e o desaparecimento desses objetos, são reveladores das práticas educacionais e suas mudanças". Isto é, o Livro não está incluído diretamente nas operações comercializáveis dos objetos escolares, mas, corrobora a formação do cidadão socialmente útil, que se mobiliza socialmente nesse período em que começa a vigorar em Santa Catarina o Regimento de 1911 e 1914.

No cenário nacional, segundo Marta Carvalho (1989) "[...] a educação ganha um estatuto de peça fundamental de uma política de valorização do homem como fator de produção e de integração". (CARVALHO,1989, p. 17). Não obstante, o Livro de Honra aparece, como uma forma de forjar as condutas esperadas pela sociedade para o homem em formação, pois seu uso conduz para a dinâmica do mérito e para os signos do cidadão socialmente útil.

Claro que não está implícito no art. 197 do Regimento Interno dos Grupos Escolares do Estado de Santa Catarina, que terá mérito o aluno que corresponder aos intentos do cidadão socialmente útil, mas se opera no ambiente escolar uma seletividade ou categorização para incutir no aluno a honra ao mérito. Nesse sentido, o Livro de Honra se potencializa como um artefato escolar para mapear os sujeitos de honra e de mérito da escola.

A questão já abordada sobre a categorização fica mais evidente no trato da honra ao mérito. Por exemplo, no Regimento de 1911 de Santa Catarina, estava explícito uma objetivação de honra, mas já no documento de 1914 aparece o mérito seguido da palavra honra, que configurou uma aproximação dos princípios meritocráticos que perpassam as ações políticas de poder-saber no mundo social. Segundo Appiah (2012), o mérito encerra-se na perspectiva do talento e por mais que se criem alterações sociais que possam modificar o significado da honra, ainda se mantém a hierarquização que categoriza os sujeitos.

Além disso, para o autor, a relação de respeito com o outro também está vinculada à honra e esta sofre alterações conforme o tempo e o espaço em que são produzidas. Contudo, de acordo com Appiah (2012), há um equívoco em criar códigos e mundos de honra quando esta favorece quem já é favorecido. O que, para o autor, remete à uma prática do desrespeito. Isso parece indicar que a presença e permanência do Livro induz à distinção e à elevação daquele que já é favorecido socialmente.

No caso da honra ao mérito na escola, afunila-se o princípio de emulação latente de justiça para com os honrados, ela provoca, face ao privilégio, um conjunto de desigualdades, através do mérito. O que remete aos argumentos de Gouvêa (2008) sobre a individualização do aluno. Aqui vale também o pensamento de Dubet (1996) "Uma escola justa não pode se limitar a selecionar os que têm mais mérito, ela deve também se preocupar com a sorte dos vencidos". (DUBET, 1996 apud VALLE, 2010, p. 33).

A presença do Livro podia deixar latente a tentativa de harmonização social buscada por um determinado grupo da sociedade, operando o poder-saber como um instrumento político e de força entre as classes que frequentavam o Grupo Escolar. Essa distinção fica mais evidente no quadro de sobrenomes ${ }^{20}$ que nele impera. $O$ Regimento

${ }^{20}$ Conforme enunciado por um dos alunos egressos, havia as famílias tradicionais presentes na cidade de 
Interno dos Grupos Escolares do Estado de Santa Catarina de 1914, apresenta a forma organizativa necessária do livro de honra. O Capítulo VI, Da Disciplina Effectiva, boletins indica as configurações e formas com as quais a escola deve tratar da disciplina na relação castigo e premiação. Assim começa o Art. 192: "Como meio disciplinar são autorizados prêmios e castigos". (Grifo nosso). Nesse sentido, o Capítulo VI também informa sobre como inscrever o nome do aluno no livro de honra.

Ali, seguem outras orientações sobre as formas de estimular e não punir. No que tange a essa forma de estimulo para a inscrição no livro de honra afirma-se no Art. 197 "O alumno que apresentar o boletim nos termos do artigo antecedente, durante dois trimestres ainda terá direito á inscripção do seu nome no livro de honra para os alumnos $[\ldots] "$.

O artigo anterior, Art. 196, a que se refere o Art. 197 afirma que:

O elogio perante todos os alunos do estabelecimento será feito quando, além de notas optimas de comportamento e de aplicação, ainda o alunno apresentar o boletim do trimestre sem uma só falta, retirada e marca tarde.

A força que este artigo tem pode ser identificada quando em 1918 o jornal O Dia divulga os alunos elogiados perante os outros do Grupo Escolar Lauro Müller, sendo a primeira em 10 de maio e a outra em 8 de agosto. Essas duas matérias ressaltam que os alunos obtiveram notas boas em comportamento e aplicação, sendo que uma delas informa que o diretor solicita que os demais alunos não elogiados sigam os exemplos daqueles.

Nesse cenário, em que os alunos e a proposição de elogios a eles são divulgados fora do universo escolar, é interessante perceber que o regimento não solicita esta prática de publicação. A situação apresentada explicita o que havíamos indicado a respeito de uma categorização que eleva, no caso da publicização, à hierarquização desses sujeitos de honra.

A divulgação da honra merece uma reflexão, pois quando uma punição, elogio ou honraria encerra-se na instituição, que cria e compartilha esta gramática, supõe-se que qualquer uma dessas ações fique restrita aos seus praticantes, que por sua vez, estão em consenso com a instituição. Todavia, conforme Appiah (2012), quando estes atos são divulgados na imprensa, os outros membros da sociedade, que não compartilham desses códigos, ora se apropriam ora modificam o seu sentido. Assim, através dos jornais, todos aqueles indivíduos externos à escola, que por ventura já detinham tais códigos e outros que passaram a conhecê-los faz com que o conteúdo divulgado passe a ser absorvido, avaliado ou refutado. $O$ que produz desdobramentos esperados ou não.

Aliado a isto, no Art. 193, parte do Capítulo VI que trata deste assunto dos

Florianópolis na década de 30, quando ele estudou no Grupo Escolar Lauro Müller. Isso se evidencia ao se encontrar uma correlação entre os "ilustres moradores de Florianópolis" no período, e os sobrenomes dos alunos que assinaram o Livro de Honra. Assim, o perdurar desse objeto memória configura um éthos institucional de honra que extrapola as páginas do Livro e se aninha nas questões sociais de reconhecimento posto na sociedade. Recorreu-se aos livros: História de Santa Catarina (1970) Segundo Volume; Biografias de Catarinenses Notáveis (2001) e Somos Todos Manezinhos (1998) para se fazer um breve comparativo entre os sobrenomes inscritos no Livro de Honra e os "ilustres moradores da Ilha". Os livros citados fazem parte do acervo da Casa da Memória. 
prêmios $^{21}$ e castigos, recomenda-se ao professor em seu $\S 1^{\circ}$, que saiba diferenciar o que é aplicação de aproveitamento ${ }^{22}$. De acordo com o texto, o sentido que o professor deve atribuir para aplicação seria:

A applicação será deduzida do esforço e da dedicação que manifestar o alunno no desempenho de seus deveres; não devendo o professor confundir applicação com o aproveitamento; esta qualidade será apreciada somente para as promoções.

Ainda que se solicitasse a diferenciação entre as notas, tais como aproveitamento e aplicação, esforço e empenho, no relato da professora Ada Biccochi Ramos ${ }^{23}$ os professores, na prática, ignoravam os critérios do artigo:

[...] se em três meses consecutivos o aluno tirasse tudo dez, recebia a honra ao mérito e, se fosse oito ou nove, recebia a menção honrosa. A menção honrosa era um cartão que tinha o nome do estabelecimento, do aluno, a classe em que ele estava. Tirava-se a menção honrosa por ter tirado naquele trimestre as notas tais e tais, por exemplo, oito. Era uma espécie de incentivo para o aluno estudar. Nós tínhamos um livro onde constava o nome de quem recebia o honra ao mérito, porque durante aquele trimestre havia tirado nota dez. Era essa a recompensa.

O artigo 197 não indica diretamente uma forma disciplinar para inscrever o nome no livro de honra, entretanto, se incursionarmos para o modelo de Boletins ${ }^{24}$, de escrituração ${ }^{25}$ e das situações da disciplina escolar (Título VIII), podemos encontrar indícios de um disciplinamento voltado ao bom comportamento, asseio, aos valores patrióticos, bem como à assiduidade e o sentimento de honra.

Nos relatórios de 1950 do Grupo Escolar Lauro Müller, como parte dos relatos sobre disciplina, encontramos as penas aplicadas aos alunos para quem "não basta bom conselho, a palavra amiga" (RELATÓRIO, 1950, p. 5). Descreve-se o quantitativo de alunos e as penas regulamentares aplicadas, sem os respectivos nomes, e também no mesmo item, constam as informações sobre o número de inscritos no Livro, salientando a presença de cartões de honra ao mérito que lhes foram distribuídos juntamente com prêmios. Neste mesmo documento há duas fotos da festividade de coroação de reis, da

${ }^{21}$ No jornal O Dia, de 4 de janeiro de 1916, aparece uma matéria sobre as festividades no encerramento do ano letivo do Grupo Escolar Lauro Müller. No evento houve a distribuição de prêmios aos alunos que se sobressaíram na classe e que tiveram trabalhos premiados. Consta no texto que os prêmios foram contribuições de empresas importantes do comércio e de pessoas ilustres da cidade.

22 Notou-se que, com o regimento de 1914, as aprovações apresentavam diferenças, pois havia aquelas que eram com distinção. No Jornal O Dia, de 30 de novembro de 1917, faz parte da matéria divulgada o nome dos alunos da seção masculina e feminina aprovados no quarto ano com e sem distinção.

${ }^{23}$ Ver Silva; Shueröff (2010).

$24 \mathrm{O}$ modelo de Boletins que compõe o Título V, sobre as folhas dos boletins, ou mesmo o Título IV, que trata da "escripturação", com destaque nos Capítulos VIII (livro de penas) e IX (livro de chamadas), solicita ao professor que na chamada exista um registro distinguindo alunos estrangeiros de brasileiros junto aos nomes, inclusive para os eliminados; no livro de chamada exige-se informações semanais sobre comportamento e aplicação; os que tiveram notas boas em comportamento não podem ser encaminhados ao diretor para registro de penas, salvo exceções quando a autoridade saiba de algum fato.

25 Conforme divulga o jornal O Dia, de 6 de novembro de 1914, no Grupo Escolar Lauro Müller foram proferidas palestras pedagógicas pelo Inspetor Geral de Ensino, as quais assistiram professores e praticantes (sujeitos que auxiliavam e escrituravam os livros e documentos) dos Grupos Escolares da capital. Dentre os temas abordados estava o processo de escrituração usado pela escola, ressaltando todos aqueles que constam no regimento interno do referido período, salientando o modo correto, a necessidade de o diretor ensinar aos praticantes os registros, e constituir, por meio dessas palestras, uma uniformidade do aparelho escolar. 
aplicação e da assiduidade, de quatro crianças por turno.

Segundo informações de alguns egressos ${ }^{26}$ do Grupo Escolar, não Ihes foram entregues no final da década de 1940 ou na de 50 cartões ou mesmo prêmios. Inclusive, um deles recordou que apenas assinou o livro em uma sala sem nenhuma solenidade. Diríamos que essa atitude ilustra a afirmação de Appiah (2012) de como a experiência em torno da honra é subjetiva.

A configuração da honra nas instituições mostra-nos como os sentidos do objeto vinculam-se a pressupostos políticos e pedagógicos, como afirma Souza (2009):

Em suma, caberia à escola primária a missão patriótica de edificar a nação por
meio da educação integral - entendida como educação física, intelectual e moral,
o que implicava não apenas a transmissão de conhecimentos, mas a formação do
caráter mediante a aprendizagem da disciplina social (obediência, asseio, ordem,
pontualidade, amor ao trabalho, honestidade, respeito às autoridades), virtudes
morais e valores cívicos necessários à formação da nacionalidade. (SOUZA, 2009,
p. 262).

Pode-se dizer que a cultura material escolar se constitui para essa cultura escolar em uma relação direta do corpo e dos objetos, como bem observou (SOUZA, 2007, p.167): "[...] o corpo se constrói pela materialidade que lhe é exterior." O livro de honra em uma cultura material da escola se singulariza como um rito ou prática, conferindo dimensões simbólicas quanto aos sentidos da honra, criando uma identificação dos sujeitos que ali se inscrevem.

Há uma série de significados distintos e aninhados no livro de honra. Nele deveria ser escrito, segundo as orientações expostas no Regimento Interno dos Grupos Escolares do Estado de Santa Catarina, como consta no Art. 67, o Termo de Abertura do livro. Há também a orientação de como deveriam ser apresentados os nomes dos alunos com suas respectivas séries anotadas ao lado, sendo esses escritos produzidos pelo próprio Diretor Escolar ou pelo praticante. Diante das prescrições para o Livro, não há informações possíveis para se identificar quem foram os responsáveis pela escrita, há somente assinaturas. A página de abertura expõe um desenho, que não consta como exigência, e logo no seu verso, aparece o Termo de Abertura, indicando o Art. 197 que direciona a forma e orientação para quais os alunos inscreveriam nele os seus nomes, datado de 23 de novembro de 1914, assinado pelo Diretor Luiz Pacifico das Neves e rubricado por ele até a página 15, esta com data de 1942. No final do Livro há o Termo de encerramento também com a data de 1914, o que faz supor que a escrita da data final foi realizada na mesma data do dia de abertura. Na página "um" aparece o parágrafo descritivo do termo do Art. 197 orientando os alunos como inscreverem seus nomes no Livro.

Faz-se importante destacar alguns aspectos referentes ao início do Livro, dentre eles o que trata da data inicial de seu uso, 1914. Notamos que o uso do Livro deu-se somente a partir de 1918, com a inscrição de apenas um nome. No período anterior a esse, há outros dois nomes inscritos, porém, sem data. Um desses nomes foi identificado como sendo o de um aluno que recebeu, em 1917, aprovação com distinção no terceiro ano, fato divulgado no jornal O Dia, de 1917, e que no quarto ano recebeu o elogio diante

${ }^{26} \mathrm{Em}$ contatos informais com egressos que haviam assinado o Livro de Honra. 
dos colegas, igualmente divulgado no jornal O Dia, de 1918. O outro aluno informado na matéria foi honrado. Dessa forma, a investigação mostra que os registros realmente não se iniciam em 1914. Dos nomes que antecedem 1918 apenas um não foi encontrado em nenhum outro jornal ou relatório para se saber o ano exato da sua inscrição.

Com uma provável inscrição de dois nomes entre 1916 e 1917, um nome inscrito em 1918, sete nomes em 1920, sete nomes em 1921 e novamente nomes inscritos só em 1928, o início e a periodicidade da atividade nos mostram que a operação da materialidade para absorção desse dispositivo de avaliação e demonstração na escola, não acontece no mesmo ano em que se introduz o novo regimento do Estado, 1914. Na verdade, isto sugere certa demora a ser apropriada pela cultura escolar.

Outro aspecto, que se identifica no início e que oscila no percurso do livro, seria as orientações de inscrição dos nomes associados às séries. Vejamos: de 1928 a 1938 há essa informação, de 1939 a 1960, em alguns ${ }^{27}$ anos não foram informados as séries dos alunos e a partir de 1961 até o fim dos registros, também não há tais dados.

Neste aspecto das séries é possível identificar que a partir da década de 1940, nos casos em que se colocaram as séries, havia um número maior no primeiro ano, no terceiro ano foi mais reduzido e no quarto, por vezes, menos da metade do que havia sido registrado no primeiro ano.

A assinatura do diretor inicia-se em 1928 e segue sem intervalos até 1947. Depois disso, só há uma assinatura sem data, em 1949. Os inspetores também passam a assinar a partir de 1931 e seguem até 1943. Essas assinaturas constam entre abril e agosto, não sendo, porém, no mesmo ano. Depois de 1944 os registros passam a ser entre outubro e novembro, geralmente no ano seguinte. Em 1939, 1949 e 1954 não há assinaturas de inspetores e a partir de 1957 encerram-se esses registros.

Fora a folha de rosto, no ano de 1928 aparece o primeiro desenho. Depois deste, no interior do Livro há figuras, desenhos e uma colagem que representam, de certa forma, a apropriação do sentido de honra no tempo e espaço daquele Grupo Escolar ${ }^{28}$. Um intento que pretende construir uma simbologia e significados para aquele que o vê, o aluno honrado.

Em uma breve análise iconográfica, identifica-se que o tema floral vai de 1928 a 1941 e que de 1942 até 1951 os temas estão mais relacionados a emblemas patrióticos ou símbolos dos compromissos de honra escolar. Dos patrióticos esteve presente o uso das cores verde e amarela relacionadas a diferentes figuras; a figura da bandeira do Brasil e o mapa do Estado de Santa Catarina. Dos símbolos de honraria, com algumas conexões com o patriótico e o escolar, havia a tocha olímpica, a inscrição dos três elementos de base da honra na escola (assiduidade, comportamento e aplicação), lamparina com chama acesa, ramos de café, caneta de pena, livros, a carta anunciando os honrados e crianças.

Analisando os sentidos das imagens que passam a ornar as páginas do Livro a partir de 1928, percebeu-se que: entre as imagens mais emblemáticas associadas a questões históricas ou mesmo políticas, havia um número maior de alunos que

\footnotetext{
${ }^{27}$ No período de 1939 a 1960, somente os anos de 1958 e 1959, não houve inscrição. Ainda neste mesmo período houve um intervalo de 13 anos no qual não há o registro da série que os alunos frequentavam.

${ }_{28}$ Cabe destacar que com o passar dos anos a descrição Grupo Escolar não perdura na nomeação das escolas, isso se deve às reformas da instrução pública.
} 
assinaram, assim como o tamanho dos símbolos que ornavam as páginas era maior. Um exemplo bem evidente encontra-se no ano do cinquentenário do Professor Orestes Guimarães, 1961, que apresentou 33 assinaturas, sendo que em 1958 e 1959 não houve nenhuma assinatura, e o ano subsequente apresenta somente nove assinaturas.

\section{Considerações finais}

Esse objeto, o Livro de Honra, é memória individual e coletiva, ilustrando como a escola conduziu os atributos individuais de honra para servir de mimetismo aos alunos, e de que maneira se construiu uma evocação da escola que supera as defasagens sociopolíticas do povo brasileiro. Há uma pujança importante nessa configuração do Livro de Honra: ele sintetiza a honra em uma única noção conceitual, ou seja, reunir no sujeito honrado aquele capaz de ter um bom comportamento associado à assiduidade, asseio, virtudes e outros predicados, o sujeito único e universal. De acordo com Rohder (2006):

a) Honra como atributo individual

Honra neste sentido é o valor que uma pessoa tem aos seus olhos e aos olhos da sociedade, por meio da conformação a determinadas formas de conduta. É uma reclamação pessoal de orgulho e também a aceitação do direito ao orgulho. Sentimentos, condutas, reputação e concessão de honra estariam implicados. Nas sociedades complexas, tende a haver uma fissura entre os polos do sentimento e modo de conduta e da honra como benefício outorgado (por um monarca, por exemplo). Esses diferentes critérios entram em jogo em distintos momentos históricos e de acordo com o tipo de hierarquia que se estabelece em cada sociedade.

(ROHDER, 2006, p. 105).

A ênfase aos sentidos de produzir ou promover honra nos sujeitos escolares, ancora-se na promoção de sentimentos, condutas e na própria reputação desse aluno. 0 Art. 166 do Regimento Interno do Grupo Escolar assegura que "[...] as crianças devem se habituar à ordem e à disciplina nas menores cousas." No que tange ao estabelecimento do direito à inscrição no livro de honra, há a questão do orgulho, uma vez que, os artigos que compõem o percurso legal de sua implantação, envolvem elogios diante dos outros. Os relatórios acentuam práticas não pleiteadas no campo legal, mas criadas para favorecer a inculcação de um aluno assíduo e aplicado por meio do coroamento do rei e rainha; a divulgação no jornal de nomes e atividades da escola.

Isso tudo porque não se constitui somente um atributo individual, se espera que seja disseminado o sentimento de honra enquanto instituição escolar e sujeitos daquela identidade escolar. Ou seja, é através do desenvolvimento de um éthos de honra da cultura escolar que os sujeitos escolares passam a produzir uma identidade. Isso suscita a análise de Rohder (2006) relativa aos estudos de Piit-Rivers sobre a questão da honra com relação a solidariedade social, quando ele afirma que "Os grupos sociais possuem uma honra coletiva relacionada à honra de cada membro. A conduta desonrosa de alguém se reflete na honra de todos". (ROHDER, 2006, p.106).

A análise desse objeto da cultura material escolar mostra o quanto esta materialidade, com toda a sua simbologia, projeta no sujeito um "deve ser", ao invés de estimular o que ele "é", cria-se a identidade do aluno dessa instituição escolar - o honrado. Isso pode ser um indicativo do porquê esse Livro atravessa décadas em uso, como que incorporado à cultura escolar dessa escola. 
Nesse tipo de materialidade escolar, pode-se ver experiências de sociabilidades compartilhadas e conduzidas por um éthos de honra proposto pela escola. Nas imagens e nas diferentes formas de operação com o Livro, no transcurso do tempo em que ele esteve presente naquela cultura escolar, ele pareceu conservar o rito para constituir um éthos de honra para aqueles alunos que passavam por aquela instituição e pela sociedade.

\section{Referências}

APPIAH, Kawame Anthony. O código de honra - Como ocorrem as revoluções morais. Tradução de Denise Bottmann. São Paulo: Companhia das Letras, 2012.

BARTHES, Roland. A câmara clara: notas sobre a fotografia. Tradução de Julio Castañon Guimarães. Rio de Janeiro: Nova Fronteira, 1984.

BENJAMIN, Walter. A obra de arte na era de sua reprodutibilidade técnica. In: BENJAMIN, Walter. Magia e técnica, arte e política: ensaios sobre literatura e história da cultura. Tradução de Sérgio Paulo Rouanet, 7 ed. São Paulo: Brasiliense,1994.

BORGES, J. Luis. O livro de areia. São Paulo: Companhia das Letras, 2009.

BOURDIEU, Pierre. Coisas Ditas. Tradução de Cássia R. da Silveira e Denise Moreno Pegorim; Revisão técnica Paula Montero. São Paulo: Brasiliense, 2004. Brasil, 2007.

O poder simbólico. Tradução de Fernando Tomaz. 11 ed. Rio de Janeiro: Bertrand CARVALHO, Marta M. Chagas de. A Escola e a República. São Paulo: Braziliense, 1989. CASTANHA, André Paulo. A regulamentação dos castigos e prêmios na escola primária do Século XIX. In: SEMINÁRIO NACIONAL DE ESTUDOS E PESQUISAS, VIII, HistedBr, São Paulo, 2009. Anais... Unicamp: Histedbr, São Paulo, 2009. Disponível em: <http://www.histedbr.fae.unicamp.br/acer_histedbr/seminario/seminario8/trabalhos.html>. Acesso em: 04 ago. 2013.

ESCOLANO, Agustin Benito. Las materialidades de la escuela (a modo de prefacio). In: GASPAR DA SILVA, Vera Lucia; PETRY, Marilia Gabriela (Orgs.) Objetos da escola: espaços e lugares de constituição de uma cultura material escolar (Santa Catarina Séculos XIX e XX). Florianópolis: Insular, 2012.

Patrimonio material da la escuela e historia cultural. Revista Linhas, Florianópolis, v. 11, n. 2, p. 13-28, jul/dez. 2010. Disponível em:

<http://www.periodicos.udesc.br/index.php/linhas/article/view/2125/1628>. Acesso em: 23 abr. 2013.

FOUCAULT, Michel. As Palavras e as Coisas: uma arqueologia das ciências humanas. Tradução de Salma Tannus Muchail. 9 ed. São Paulo: Martins Fontes, 2007. 2008.

Vigiar e Punir. Tradução de Raquel Ramalhete. 35 ed. Petrópolis, RJ: Vozes,

GOUVÊA, Maria Cristina de. A escolarização da meninice nas Minas Oitocentistas: a individualização do aluno. In: VEIGA, Cynthia G.; FONSECA, Thais N. de Lima e. História e Historiografia da Educação no Brasil. Belo Horizonte: Autêntica, 2008.

HOUAISS, Antônio. Dicionário Houaiss da Língua Portuguesa. Disponível em: <http://houaiss.uol.com.br/>. Acesso em 01 jul. 2013.

MORAES, Lúcio Vânio. Instrumentos de vigilâncias no educandário Manoel Gomes 
Baltazar - Maracajá -SC: "Livro Negro" e "Livro de Honra" (1961/1971). Revista II, Seminário de Linha Educação, Linguagem e Memória - SELM, Linguagem e Sociedade. [on-line], Unesc, v. 2, 2012. Disponível em:

<http://periodicos.unesc.net/index.php/SELM/article/viewFile/831/767>. Acesso em: 02 ago. 2013.

PESEZ, Jean-Marie. História da cultura material. In: LEGOFF, J. A história nova. São Paulo: Martins Fontes, 1990.

POLLAK, M. Memória e identidade social. In: Estudos Históricos, Rio de Janeiro, v. 5, n. 10, 1992.

ROHDEN, Fabíola. Para que Serve o Conceito de Honra, ainda hoje? In: Campos Revista de Antropologia Social (UFPR), v. 7, n. 2, p. 101-120, 2006. Disponível em: <http://ojs.c3sl.ufpr.br/ojs2/index.php/campos/article/view/7436>. Acesso em: 30 out. 2011.

\section{SANTA CATARINA. Acervo Documental do Grupo Escolar Lauro Müller.}

. Decreto № 588 de 22 de Abril de 1911. Regimento Interno dos Grupos Escolares do Estado de Santa Catharina. 1911. (Acervo: Arquivo Público do Estado de Santa Catarina).

. Decreto № 795 de 2 de Maio de 1914. Regimento Interno dos Grupos Escolares do Estado de Santa Catharina. 1914. (Acervo: Universidade Federal de Santa Catarina UFSC).

SILVA, Vera Lucia Gaspar da. Regulamentos para instrução: para além do ensino, as condutas. In: CONGRESSO BRASILEIRO DE HISTÓRIA DA EDUCAÇÃO - CBHE, I, Rio de Janeiro/RJ, 2000. Anais... Rio de Janeiro: UFRJ, 2000. Disponível em:

<http://www.sbhe.org.br/novo/congressos/cbhe1/anais/158_vera_lucia_g.pdf>. Acesso em: 20 jul. 2013.

SILVA, Vera Lucia Gaspar da; SHUERÖFF, Dilce. Memória Docente: história de professores catarinenses (1890-1950). Florianópolis: UDESC, 2010.

SOUZA, Rosa de Fátima. Alicerces da pátria: História da escola primária no Estado de São Paulo (1890-1976). Campinas, SP: Mercado das Letras, 2009.

. História da Cultura Material Escolar: Um balanço inicial. In: BENCOSTA, Marcus Levy (Org.). Culturas Escolares, Saberes e Práticas Educativas: itinerários históricos. São Paulo: Cortez, 2007.

TEIVE, Gladys Mary G. Grupo escolar e produção do sujeito moderno: um estudo sobre o currículo e a cultura escolar dos primeiros grupos escolares catarinenses (1911-1935).

Revista História da Educação, v. 13, n. 29, 2009. Disponível em:

<http://seer.ufrgs.br/asphe/article/view/28927/pdf>. Acesso em: 02 jul. 2013.

VALLE, lone R. Justiça na escola: das desigualdades justas à igualdade sem adjetivos! In: VALLE, Ione R.; SILVA, Vera Lucia Gaspar da; DAROS, Maria das Dores (Orgs.)

Educação escolar e justiça social. Florianópolis: NUR, 2010.

LISLEY CANOLA TREIS TEIXEIRA é doutoranda em Educação, Linha de Pesquisa Sociologia e História da Educação, Programa de Pós-Graduação em Educação da Universidade Federal de Santa Catarina.

Endereço: Rua Capitão Américo, 103, ap. 504 A - Córrego Grande - 88037-060 Florianópolis/SC - Brasil.

E-mail: canolatt@uol.com.br 
LUANI DE LIZ SOUZA é Doutora em Educação, Linha de Pesquisa História e Historiografia da Educação, Programa de Pós-Graduação em Educação da Universidade do Estado de Santa Catarina.

Endereço: Rua Rodolfo Manoel Bento, 85, ap. 204 - Carvoeira - 88040-490 Florianópolis/SC - Brasil.

E-mail: luani.liz.souza@gmail.com

Recebido em 01 de janeiro de 2015.

Aceito em 23 de setembro de 2015. 